\title{
Unusual Spectral Change Due to a Cyanine Dye Adsorbed on an Inorganic Layered Material upon Photoirradiation
}

\author{
Mari Ishihara*, Ryuji Hirase, Hideki Yoshioka \\ Hyogo Prefectural Institute of Technology, Kobe, Japan \\ Email: ${ }^{*}$ mari@hyogo-kg.jp
}

Received 9 October 2014; revised 22 October 2014; accepted 20 November 2014

Academic Editor: Yarub Al-Douri, University Malaysia Perlis, Malaysia

Copyright (C) 2014 by authors and Scientific Research Publishing Inc.

This work is licensed under the Creative Commons Attribution International License (CC BY). http://creativecommons.org/licenses/by/4.0/

\section{(c) (i) Open Access}

\begin{abstract}
Photoinduced spectral change can be utilized for various optical devices. The photoinduced spectral change due to an organic dye was demonstrated for the organic-inorganic hybrid film without the aid of photochromism with a simple preparation method for the first time. By the hybridization of a cyanine dye of 2-[5-(1,3-dihydro-3,3-dimethyl-1-octadecyl-2H-indol-2-ylidene)1,3-pentadienyl]-3,3-dimethyl-1-octadecyl-3H-indolium perchlorate (NK3175) with an inorganic layered material of cation-exchangeable clay, smectite ( $\mathrm{SWN}$ ), a spectral change attributed to NK3175 was generated upon the irradiation of UV light. This result might serve as useful information on the methodology to produce optically controlled function for photoresponsive systems. Furthermore, the hybrid film of SWN and NK3175 was characterized by the use of XRD and FT-IR measurements. NK3175 molecules adsorbed onto external surfaces of SWN were confined by oriented SWN. It was suggested that the enhanced intermolecular interaction between NK3175 molecules caused by the hybridization with SWN resulted in the change of the aggregation state of NK3175 upon the UV light irradiation, which accounts for the spectral change of NK3175.
\end{abstract}

\section{Keywords}

Photoinduced Spectral Change, Cyanine Dye, Clay, Hybrid Material

\section{Introduction}

Organic dyes have attracted much attention from both viewpoints of fundamental science and practical applica*Corresponding author.

How to cite this paper: Ishihara, M., Hirase, R. and Yoshioka, H. (2014) Unusual Spectral Change Due to a Cyanine Dye Adsorbed on an Inorganic Layered Material upon Photoirradiation. World Journal of Nano Science and Engineering, 4, $126-133$. http://dx.doi.org/10.4236/wjnse.2014.44016 
tions such as memories, switching devices, electroluminescent devices, solar cells, optical filters, etc. Change of physical properties such as optical reflectance, refractivity, and fluorescence caused by photoirradiation for photo-functional organic dyes has been utilized for various optical devices. Inorganic layered materials such as clay minerals are widely utilized as host materials for functional organic-inorganic hybrid systems due to their characteristic properties of intercalation and adsorption of organic guest species [1]-[6]. Photo-functional organic-inorganic hybrid materials with an ordered structure have been constructed by utilizing intercalation and adsorption of photo-functional organic guest species into or on clay layers [1] [2] [7]. In such cases, distances between the photo-functional organic dyes become shorter. Therefore, it is expected that intermolecular interactions between these compounds are enhanced [1] [2] [8]. In fact, the intercalation and adsorption of the photofunctional organic dyes have enabled aggregation and alignment control of the organic dyes [1] [2] [8]-[14] and have affected photochemical properties, such as fluorescence behaviors [4] [5] [7] [8] [15]-[21].

The cooperative control of physical properties of the other organic material caused by an influence of photochromism is one of the active ways to create novel photo-functional systems [22]-[30]. Photochromic compounds have been extensively studied due to their possible application in various optical devices, such as memories and switches [31]. For photochromic memories one of the most pressing problems is on the method for non-destructive readout [31]. Monitoring change in ultraviolet (UV)-visible absorption is not a feasible method for non-destructive readout of photochromic memories; therefore, several alternative methods for non-destructive readout have been demonstrated [31]. On the other hand, photochromic compounds and organic dyes can be selected, so as to that the absorption of an organic dye and two isomers of a photochromic compound are in different spectral regions for the cooperative photoresponsive systems including these compounds. Accordingly there might be a possibility that monitoring change in the UV-visible absorption without an occurrence of a reverse photo isomerization reaction can be utilized for a non-destructive readout in this system. We proposed to monitor the absorption in the UV-visible region as a non-destructive readout method for a cooperative photoresponsive system and performed the photoinduced spectral change due to a cyanine dye by the use of a simple preparation method [30]. In order to amplify a cooperative effect of photochromism, we made use of an inorganic layered material together with an organic dye and a photochromic molecule to successfully prepare the hybrid film as a novel photo-functional organic-inorganic hybrid material [30]. It was shown that an electronic absorption spectrum ascribed to the cyanine dye was significantly changed by UV light irradiation for the hybrid film of the cyanine dye, a photochromic molecule of a diarylethene, and an inorganic clay mineral, smectite, [30]. However, the further mechanism of the photoindued spectral change due to the cyanine dye for the above hybrid film is not elucidated. For the above hybrid film, smectite as well as the diarylethene is considered to play an important role in bringing about the photoinduced spectral change due to the cyanine dye. The interaction between the cyanine dye and smectite might affect the microstructure and the photoinduced spectral behavior for the above hybrid film.

In this study, we investigated the interaction between a cyanine dye and smectite and the photoinduced spectral behavior for the hybrid film of a cyanine dye and smectite. We demonstrate the interesting phenomena that without the aid of photochromism, a cyanine dye is induced to exhibit the photoresponsive property by hybridizing with an inorganic clay mineral, although a cyanine dye itself does not show any photoresponsive properties. This study is expected to give new information on the methodology to introduce optically controlled function for photoresponsive systems.

\section{Experimental}

\subsection{Materials}

A cyanine dye of 2-[5-(1,3-dihydro-3,3-dimethyl-1-octadecyl-2H-indol-2-ylidene)-1,3-pentadienyl]-3,3-dimethyl-1-octadecyl-3H-indolium perchlorate (NK3175; Hayashibara Biochemical Labs., Inc.) was used without further purification (Figure 1).

Cation-exchangeable clay, SWN (CO-OP Chemical Co., Inc.), was used as a host material. It is a type of hydrophilic smectite, and has good transparency in the visible region. The composition is $\left[\left(\mathrm{Mg}_{2.67} \mathrm{Li}_{0.33}\right)\left(\mathrm{Si}_{4} \mathrm{O}_{10}\right)\right.$ $\left.(\mathrm{OH})_{2}\right] \mathrm{Na}_{0.33}$, and the cation exchangeable capacity (CEC) is c.a. $0.6 \mathrm{meq} \cdot \mathrm{g}^{-1}$. Distilled and deionized water (conductivity $<4 \times 10^{-6} \mathrm{~S} \cdot \mathrm{cm}^{-1}$ ) and ethanol (Wako Pure Chemical Industries Co. Inc., spectroscopic grade) were used as solvents for the preparation of the organic-inorganic hybrid films. 


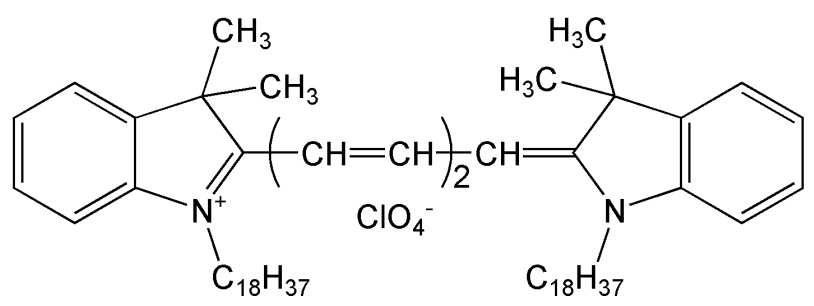

Figure 1. Chemical structure of a cyanine dye, NK3175.

\subsection{Sample Preparation}

Solution of cyanine dye of NK3175 $\left(1.5 \times 10^{-6} \mathrm{~mol}\right)$ in ethanol $(10 \mathrm{~mL})$ added to an aqueous suspension of SWN $(0.050 \mathrm{~g} / 5 \mathrm{~mL})$ and stirred for $27 \mathrm{~h}$ at $60^{\circ} \mathrm{C}$ in the dark. Obtained viscous solution was then casted on fused silica plates or Au-coated glass plates and dried at room temperature and transparent blue films were prepared. For FT-IR measurements, Au-coated glass plates were used. The obtained films are, hereafter, referred to as the hybrid films of SWN and NK3175. The ethanol solution of NK3175 $\left(2.5 \times 10^{-6} \mathrm{M}\right)$ was also prepared for comparison.

\subsection{Measurement}

Electronic absorption spectra were recorded on a Shimadzu SolidSpec-3700 spectrophotometer. X-ray diffraction (XRD) patterns were measured with a RIGAKU RINT 2500 or a RIGAKU Smart Lab diffractometer using $\mathrm{CuK} \alpha$ radiation source operating at $40 \mathrm{kV}$ and $200 \mathrm{~mA}$ as the applied voltage and current, respectively. FT-IR spectra were measured on a Nicolet is 50 FTIR at $4 \mathrm{~cm}^{-1}$ resolution. FT-IR reflection spectra of films were taken using a variable angle reflection accessory at an incident angle of 45 degrees. In the case of the measurement of polarized FT-IR spectra, a ZnSe polarizer was used. An attenuated total reflection (ATR) FT-IR spectrum of NK3175 powder was taken using Smart iTR accessory. UV light of around $254 \mathrm{~nm}$ (c.a. $1100 \mu \mathrm{W} \cdot \mathrm{cm}^{-2}$ ) was irradiated for 5 minutes using a handy UV lamp.

\section{Results and Discussion}

\subsection{Spectral Change of the Hybrid Films of SWN and NK3175 upon Photoirradiation}

Figure 2 shows electronic absorption spectra of the hybrid film of SWN and NK3175 and, for reference, ethanol solution of NK3175 before and after irradiation of UV light at $254 \mathrm{~nm}$. For the solution of NK3175, the bands at 598 and $647 \mathrm{~nm}$ were observed (Figure 2(a)). These peaks were not changed by UV light irradiation at $254 \mathrm{~nm}$. These bands could be ascribed to H-dimers and monomers of NK3175, respectively, according to the previous reports [8] [16] [32]. Before the UV light irradiation, the absorption bands at 603 and $652 \mathrm{~nm}$ ascribed to H-dimers and monomers of NK3175, respectively, were lightly red-shifted from those for the solution of NK3175, which were caused by adsorption of cationic NK3175 on negatively charged SWN [16]-[18] [33]. In addition, the relative intensity of the band at $603 \mathrm{~nm}$ to the band at $652 \mathrm{~nm}$ in the hybrid film in comparison with that in the solution of NK3175 increased, indicating that hybridization with SWN promotes the formation of H-dimers of NK3175.

On the other hand, it was interestingly found that in the hybrid film of SWN and NK3175 the spectral change due to NK3175 was occurred upon UV light irradiation at $254 \mathrm{~nm}$. Upon the irradiation of UV light, the bands at 412 and $531 \mathrm{~nm}$ were clearly appeared, whereas the bands at 603 and $652 \mathrm{~nm}$ significantly decreased (Figure 2(c)). This change was essentially in good accord with our previous report which demonstrate a spectral change in the hybrid films of SWN, NK3175 and a diarylethene [30]. The change was somewhat smaller in this study probably because of the absence of the movement accompanied by a photochromic reaction [30]. The irradiated spectrum gradually returned to the one before UV light irradiation and reached a stationary state on keeping this film for about $23 \mathrm{~h}$ in the dark at room temperature, which indicates the observed spectral change do not arise from the photodecomposition of NK3175. Upon repeated irradiation of UV light, the similar spectral change took place as in the first time again. According to the previous report [8] [33], we presumed that the bands at 412 and $531 \mathrm{~nm}$ were ascribed to higher-order H-aggregates of NK3175 resulted from disaggregated H-dimers and monomers of NK3175. After UV light irradiation, after keeping this film in the dark the slow spectral change occurred for hours. It was reported that the aggregation of a cationic dye solution was instantly formed in 
the dispersions after mixing a cationic dye with a clay mineral, and then disaggregation of a cationic dye proceed slowly for hours and days [16] [34]. We assume that a similar situation occurs here. We have found that the similar spectral change due to other cyanine dyes, such as 2-[7-(1,3-dihydro-3,3-dimethyl-1-octadecyl-2H-indol2-ylidene)-1,3,5-heptatrienyl]-3,3-dimethyl-1-octadecyl-3H-indolium perchlorate and 3-ethyl-2-[5-(3-ethyl-2(3H)-benzoxazolylidene)-1,3-pentadienyl] benzoxazolium iodide also occurred upon UV light irradiation for the hybrid films with SWN.

\subsection{Spectral Change of the Hybrid Film of SWN and NK3175 upon Heating}

Figure 3 shows the electronic absorption spectra of the hybrid film of SWN and NK3175 on heating. Upon heating this film at $80^{\circ} \mathrm{C}$ for $1 \mathrm{~h}$, the bands at $652 \mathrm{~nm}$ slightly shifted to $648 \mathrm{~nm}$, which implies a change of a polar environment around NK3175 molecules [18] [35]. The spectral change such as the appeared bands at 531 and $412 \mathrm{~nm}$ and the decreased bands at 652 and $603 \mathrm{~nm}$ observed upon the UV light irradiation were not recognized upon heating. From these results, it was confirmed that the spectral change due to NK3175 upon UV light irradiation was caused not by heating but by photoirradiation.

\subsection{X-Ray Diffraction and FT-IR Reflection Spectra of the Hybrid Film of SWN and NK3175}

Figure 4 shows XRD patterns of the hybrid film of SWN and NK3175 and a casted film of SWN which was obtained from the suspension of SWN $(0.051 \mathrm{~g})$ in distilled and deionized water $(5 \mathrm{~mL})$ and ethanol $(25 \mathrm{~mL})$ stirred for $30 \mathrm{~h}$ at $60^{\circ} \mathrm{C}$. The 100 reflections were observed at $\mathrm{d}=14.7 \AA$ (6.02 degree) and $14.2 \AA$ (6.21 degree),

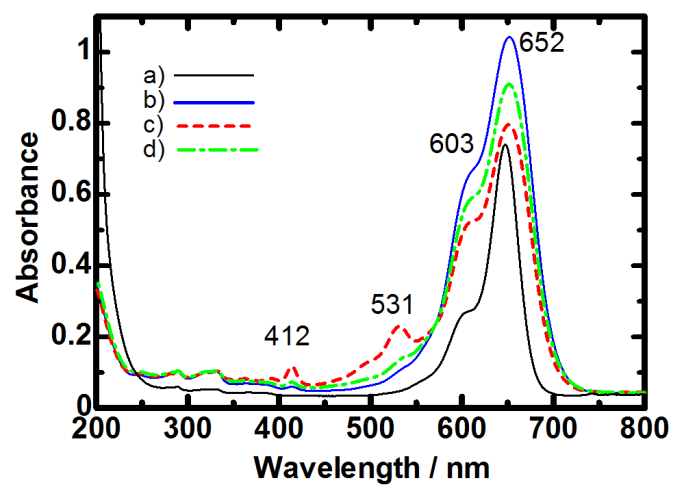

Figure 2. Electronic absorption spectra of a) the ethanol solution of NK3175 and the hybrid film of SWN and NK3175, b) before irradiation, c) after UV light $(\lambda=254 \mathrm{~nm})$ irradiation, and d) after keeping for $23 \mathrm{~h}$ in the dark at room temperature.

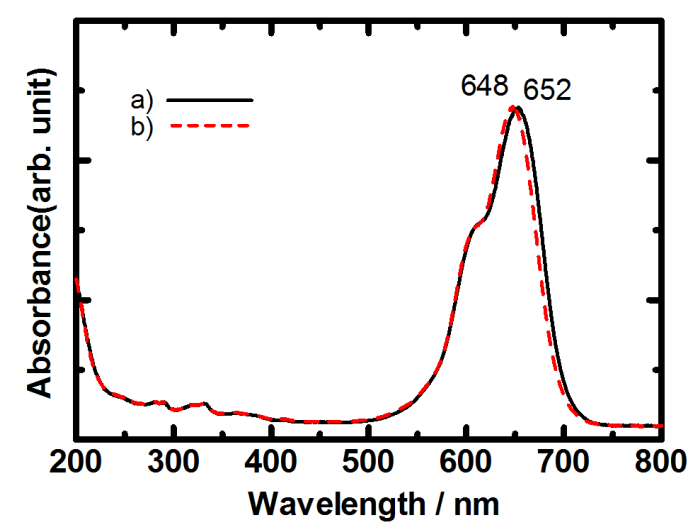

Figure 3. Electronic absorption spectra of the hybrid film of SWN and NK3175: a) before heating, b) after heating at $80^{\circ} \mathrm{C}$ for $60 \mathrm{~min}$. 


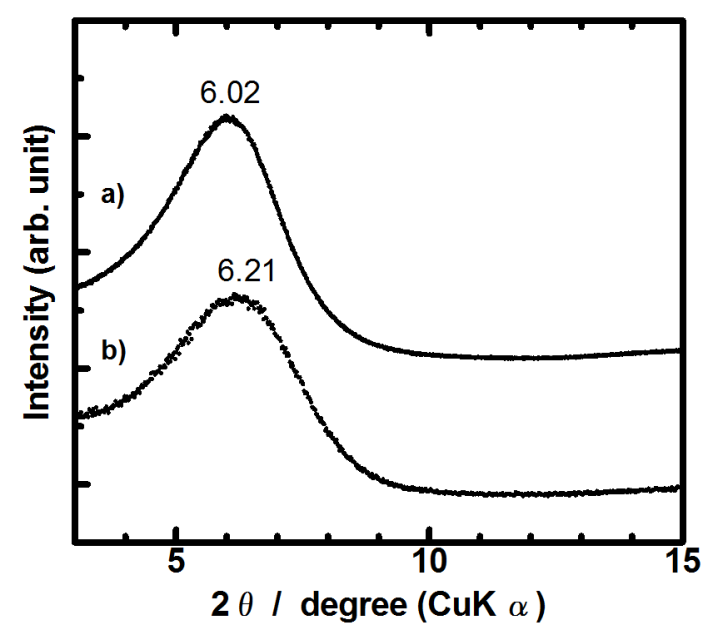

Figure 4. XRD patterns of a) the hybrid film of SWN and NK3175 and b) the casted film of SWN.

respectively. The slight enhancement of the $d_{001}$ values indicates that NK3175 molecules were not intercalated into SWN layers.

FT-IR spectroscopy revealed the adsorption of a cationic dye of NK3175 on the anionic surface of SWN which appreciably oriented parallelism to the surface of the hybrid film of SWN and NK3175. Figure 5 and Figure 6 show the FT-IR spectra of the hybrid film of SWN and NK3175. In Figure 5(a), the bands at 1491, 1481 , and $1456 \mathrm{~cm}^{-1}$ are assignable to the stretching vibration of the central conjugated system of NK3175. The bands at 1481 and $1456 \mathrm{~cm}^{-1}$ might contain a contribution from the in-plane skeletal vibration of the phenyl ring and a contribution from the $\mathrm{CH}_{3}$ asymmetric deformation vibration of NK3175, respectively [36]-[38]. The bands at 1491, 1481, and $1456 \mathrm{~cm}^{-1}$ were shifted and changed in relative intensity compared to those for NK3175 powder (Figure 5(b)). Moreover, the broad band around $1388 \mathrm{~cm}^{-1}$ and the band at $1335 \mathrm{~cm}^{-1}$ for the hybrid film (Figure 5(a)) were relatively smaller than those in NK3175 powder (Figure 5(b)). These bands are attributable to atomic motions in the methine chain of NK3175 and the band around $1388 \mathrm{~cm}^{-1}$ might contain a contribution from the $\mathrm{CH}_{3}$ symmetric deformation mode of NK3175 [36]-[38]. These were attributable to the adsorption of the cationic dye of NK3175 on the negatively charged external surface of SWN, which corresponds to the results from the electronic absorption spectra. Figure 6 shows the polarization dependency on the bands ascribed to the Si-O vibrations of SWN. In the $p$-polarized spectrum the bands at $1090 \mathrm{~cm}^{-1}$ and $977 \mathrm{~cm}^{-1}$ are assignable to the out-of-plane Si-O stretching and the in-plane Si-O stretching vibration of SWN, respectively. The band at $965 \mathrm{~cm}^{-1}$ observed in the s-polarized spectrum is attributable to the in-plane Si-O stretching vibration of SWN [33] [39]. These suggest that tetrahedral layers of SWN considerably oriented parallel to the surface of the hybrid film of SWN and NK3175 [30] [33] [39].

Taking into accounts the above results, one of the possible mechanism of the spectral change due to NK3175 induced by photoirradiation for the hybrid film of SWN and NK3175 is as follows; NK3175 molecules adsorbed onto the external surface of SWN are confined by the oriented SWN to approach each other. This situation is considered to enhance the intermolecular interactions between NK3175 molecules. Computational study for cyanine dyes previously reported that upon photoexcitation, the electron density on the methine chain increased, leading to the rotation of the methine chain [40]. For the hybrid film of SWN and NK3175, in a similar manner, upon photoirradiation the electron density on the methine chain of NK3175 somewhat increases, giving rise to the rotation of the methine chain, that is, the conformational change of NK3175. In the present case, NK3175 molecules approach each other so that they could strongly interact to form unique aggregation such as higher-order H-aggregates of NK3175 upon UV light irradiation. Consequently, the spectral change due to NK3175 is induced by photoirradiation for the hybrid film of SWN and NK3175. The spectral change due to NK3175 upon photoirradiation was enhanced in the hybrid film of SWN, NK3175 and the diarylethene [30] in comparison with that in the hybrid film of SWN and NK3175. It is probably because not only the above effect but also photochromism of the diarylethene which affected the state of aggregation of NK3175 have contributed to the enhanced spectral change upon photoirradiation in the hybrid film of SWN, NK3175 and the diarylethene [30]. 


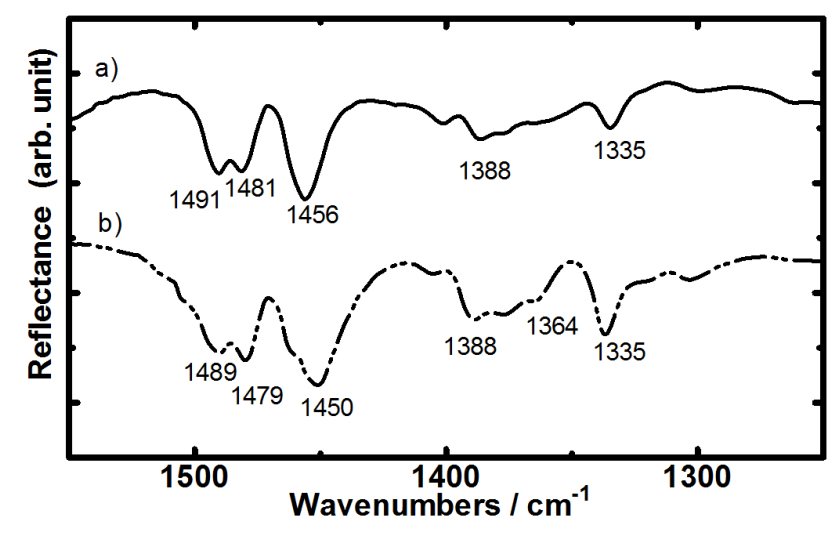

Figure 5. Unpolarized FT-IR spectra of a) the hybrid film of SWN and NK3175 and b) NK3175 powder.

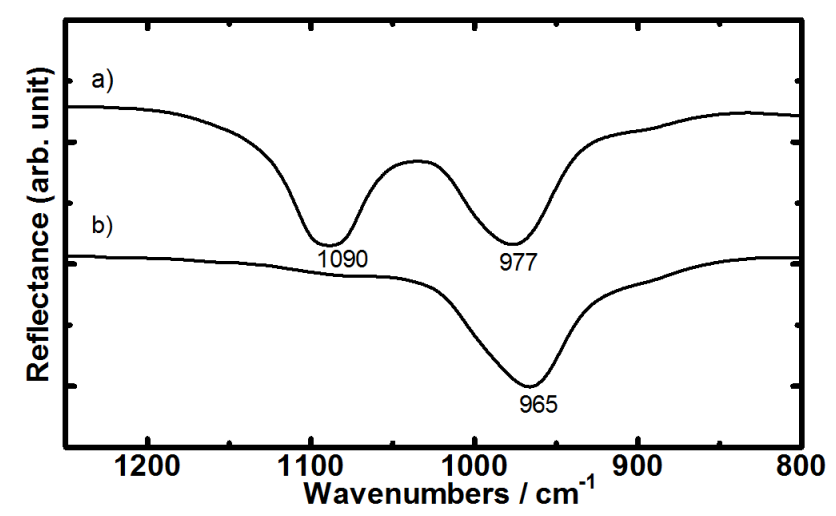

Figure 6. Polarized FT-IR spectra in the Si-O stretching vibration region of the hybrid film of SWN and NK3175 with a) p-polarization and b) s-polarization.

\section{Conclusion}

The unusual spectral change ascribed to a cyanine dye was induced upon the irradiation of UV light without the help of photochromism, for the first time, by hybridizing a cyanine dye with an inorganic clay mineral with a simple preparation method. This result is expected to provide new information on the methodology to produce optically controlled function for photoresponsive systems. In addition, for the hybrid film of smectite of SWN and a cyanine dye of NK3175, it was suggested that NK3175 molecules adsorbed onto the external surface of SWN were confined by oriented SWN, enhancing the intermolecular interaction of NK3175 molecules, which induced the change of the state of aggregation of NK3175 upon UV light irradiation.

\section{Acknowledgements}

We would like to thank Dr. Nobutaka Tanigaki and Dr. Keiko Tawa of National Institute for Advanced Industrial Science and Technology and Professor Hideyuki Nakano of Muroran Institute of Technology for their valuable discussions and advices. This work was partly supported by Research for Promoting Technological Seeds type A and Adaptable and Seamless Technology Transfer Program through Target-driven R \& D from the Japan Science and Technology Agency (JST).

\section{References}

[1] Ogawa, M. and Kuroda, K. (1995) Photofunctions of Intercalation Compounds. Chemical Reviews, 95, 399-438. http://dx.doi.org/10.1021/cr00034a005

[2] Shichi, T. and Takagi, K. (2000) Clay Minerals as Photochemical Reaction Fields. Journal of Photochemistry and 
Photobiology C: Photochemistry Reviews, 1, 113-130. http://dx.doi.org/10.1016/S1389-5567(00)00008-3

[3] Takagi, S., Shimada, T., Ishida, Y., Fujimura, T., Masui, D., Tachibana, H., Eguchi, M. and Inoue, H. (2013) SizeMatching Effect on Inorganic Nanosheets: Control of Distance, Alignment and Orientation of Molecular Adsorption as a Bottom-Up Methodology for Nanomaterials. Langmuir, 29, 2108-2119. http://dx.doi.org/10.1021/la3034808

[4] Zhou, C.H., Shen, Z.F., Liu, L.H. and Liu, S.M. (2011) Preparation and Functionality of Clay-Containing Films. Journal of Material Chemistry, 21, 15132-15153. http://dx.doi.org/10.1039/c1jm11479d

[5] Ras, R.H.A., Umemura, Y., Johnston, C.T., Yamagishi, A. and Schoonheydt, R.A. (2007) Ultrathin Hybrid Films of Clay Minerals. Physical Chemistry Chemical Physics, 9, 918-932. http://dx.doi.org/10.1039/b610698f

[6] Ogawa, M., Ishii, I., Miyamoto, N. and Kuroda, K. (2003) Intercalation of a Cationic Azobenzene into Montmorillonite. Applied Clay Science, 22, 179-185. http://dx.doi.org/10.1016/S0169-1317(02)00157-6

[7] Tsukamoto, T., Shimada, T. and Takagi, S. (2013) Unique Photochemical Properties of p-Substituted Cationic Triphenylbenzene Derivatives on a Clay Layer Surface. The Journal of Physical Chemistry C, 117, 2774-2779. http://dx.doi.org/10.1021/jp3092144

[8] Bujdak, J. (2006) Effect of the Layer Charge of Clay Minerals on Optical Properties of Organic Dyes. Applied Clay Science, 34, 58-73. http://dx.doi.org/10.1016/j.clay.2006.02.011

[9] Estevez, M.J.T, Arbeloa, F.L. and Arbeloa, T.L. (1994) On the Monomeric and Dimeric States of Rhodamine 6G Adsorbed on Laponite B Surfaces. Journal of Colloid and Interface Science, 162, 412-417. http://dx.doi.org/10.1006/jcis.1994.1055

[10] Yariv, S., Nasser, A. and Baron, P. (1990) Metachromasy in Clay Minerals. Spectroscopic Study of the Adsorption of Crystal Violet by Laponite. Journal of the Chemical Society, Faraday Transactions, 86, 1593-1598. http://dx.doi.org/10.1039/ft9908601593

[11] Lucia, L.A., Yui, T., Sasai, R., Yoshida, H., Takagi, S., Takagi, K., Whitten, D.G. and Inoue, H. (2003) Enhanced Aggregation Behavior Antimony (V) Porphyrins in Polyfluorinated Surfactant/Clay Hybrid Microenvironment. The Journal of Physical Chemistry B, 107, 3789-3797. http://dx.doi.org/10.1021/jp026648a

[12] Takagi, K., Kurematsu, T. and Sawaki, Y. (1991) Intercalation and Photochromism of Spiropyrans on Clay Interlayeres. Journal of the Chemical Society, Perkin Transactions, 2, 1517-1522. http://dx.doi.org/10.1039/p29910001517

[13] Sasai, R., Ogiso, H., Shindachi, I., Shichi, T. and Takagi, K. (2000) Photochromism in Oriented Thin Films Prepared by the Hybridization of Diarylethenes in Clay Interlayers. Tetrahedron, 56, 6979-6984. http://dx.doi.org/10.1016/S0040-4020(00)00519-6

[14] Iyi, N., Kurashima, K. and Fujita, T. (2002) Orientation of an Organic Anion and Second-Staging Structure in Layered Double-Hydroxide Intercalates. Chemistry of Materials, 14, 583-589. http://dx.doi.org/10.1021/cm0105211

[15] Bujdak, J., Iyi, N. and Sasai, R. (2004) Spectral Properties, Formation of Dye Molecular Aggregates and Reactions in Rhodamine 6G/Layered Silicates Dispersions. The Journal of Physical Chemistry B, 108, 4470-4477. http://dx.doi.org/10.1021/jp037607x

[16] Mishra, A., Behera, R.K., Behera, P.K., Mishra, B.K. and Behera, G.B. (2000) Cyanines during the 1990s: A Review. Chemical Reviews, 100, 1973-2012. http://dx.doi.org/10.1021/cr990402t

[17] Ogawa, M., Kawai, R. and Kuroda, K. (1996) Adsorption and Aggregation of a Cationic Cyanine Dye on Smectites. The Journal of Physical Chemistry, 100, 16218-16221. http://dx.doi.org/10.1021/jp9602610

[18] Bujdak, J., Martinez, V.M., Arbeloa, F.L. and Iyi, N. (2007) Spectral Properties of Rhodamine 3B Adsorbed on the Surface of Montmorillonites with Variable Layer Charge. Langmuir, 23, 1851-1859. http://dx.doi.org/10.1021/la062437b

[19] Sasai, R., Iyi, N., Fujita, T., Arbeloa, F.L., Martinez, V., Takagi, K. and Itoh, H. (2004) Luminescence Properties of Rhodamine 6G Intercalated in Surfactant/Clay Hybrid Thin Solid Films. Langmuir, 20, 4715-4719. http://dx.doi.org/10.1021/la049584z

[20] Suzuki, Y., Tenma, Y., Nishioka, Y., Kamada, K., Ohta, K. and Kawamata, J. (2011) Efficient Two-Photon Absorption Materials Consisting of Cationic Dyes and Clay Minerals. The Journal of Physical Chemistry C, 115, 20653-20661. http://dx.doi.org/10.1021/jp203809b

[21] Nakato, T., Kusunoki, K., Yoshizawa, K., Kuroda, K. and Kaneko, M. (1995) Photoluminescence of Tris(2,2’-bipyridine)ruthenium(II) Ions Intercalated in Layered Niobates and Titanates: Effect of Interlayer Structure on Host-Guest and Guest-Guest Interactions. The Journal of Physical Chemistry, 99, 17896-17905. http://dx.doi.org/10.1021/j100051a015

[22] Ichimura, K. (2000) Photoalignment of Liquid-Crystal Systems. Chemical Reviews, 100, 1847-1874. http://dx.doi.org/10.1021/cr980079e

[23] Ruslim, C., Hashimoto, M., Matsunaga, D., Tamaki, T. and Ichimura, K. (2004) Optical and Surface Morphological 
Properties of Polarizing Films Fabricated from a Chromonic Dye by the Photoalignment Technique. Langmuir, 20, 95-100. http://dx.doi.org/10.1021/la035366e

[24] Seki, T. (2007) Smart Photoresponsive Polymer Systems Organized in Two Dimensions. Bulletin of the Chemical Society of Japan, 80, 2084-2109. http://dx.doi.org/10.1246/bcsj.80.2084

[25] O’Neill, M. and Kelly, S.M. (2011) Ordered Materials for Organic Electronics and Photonics. Advanced Materials, 23, 566-584. http://dx.doi.org/10.1002/adma.201002884

[26] Kawatsuki, N. (2011) Photoalignment and Photoinduced Molecular Reorientation of Photosensitive Materials. Chemistry Letters, 40, 548-554. http://dx.doi.org/10.1246/cl.2011.548

[27] Kurihara, S., Nomitama, S. and Nonaka, T. (2001) Photochemical Control of the Macrostructure of Cholesteric Liquid Crystals by Means of Photoisomerization of Chiral Azobenzene Molecules. Chemistry of Materials, 13, 1992-1997. http://dx.doi.org/10.1021/cm0007555

[28] Moriyama, M., Mizoshita, N., Yokota, T., Kashimoto, K. and Kato, T. (2003) Photoresponsive Anisotropic Soft Solids: Liquid-Crystalline Physical Gels Based on a Chiral Photochromic Gelator. Advanced Materials, 15, 1335-1338. http://dx.doi.org/10.1002/adma.200305056

[29] Matsumoto, M., Tachibana, H., Sato, F. and Terrettaz, S. (1997) Photoinduced Self-Organization in Langmuir-Blodgett Films. The Journal of Physical Chemistry B, 101, 702-704. http://dx.doi.org/10.1021/jp9629093

[30] Ishihara, M., Hirase, R., Mori, M., Yoshioka, H. and Ueda, Y. (2009) Photoinduced Spectral Changes in Hybrid Thin Films of Functional Dyes and Inorganic Layered Material. Thin Solid Films, 518, 857-860. http://dx.doi.org/10.1016/j.tsf.2009.07.103

[31] Irie, M. (2000) Diarylethenes for Memories and Switches. Chemical Reviews, 100, 1685-1716. http://dx.doi.org/10.1021/cr980069d

[32] Bujdak, J. and Iyi, N. (2006) Molecular Aggregation of Rhodamine Dyes in Dispersions of Layered Silicates: Influence of Dye Molecular Structure and Silicate Properties. The Journal of Physical Chemistry B, 110, 2180-2186. http://dx.doi.org/10.1021/jp0553378

[33] Iyi, N., Sasai, R., Fujita, T., Deguchi, T., Sota, T., Arbeloa, F.L. and Kitamura, K. (2002) Orientation and Aggregation of Cationic Laser Dyes in a Fluoromica: Polarized Spectrometry Studies. Applied Clay Science, 22, 125-136. http://dx.doi.org/10.1016/S0169-1317(02)00144-8

[34] Bujdak, J., Iyi, N. and Fujita, T. (2002) The Aggregation of Methylene Blue in Montmorillonite Dispersions. Clay Minerals, 37, 121-133. http://dx.doi.org/10.1180/0009855023710022

[35] Neumann, M.G., Schmidt, C.C. and Gessner, F. (1996) Time-Dependent Spectrophotometric Study of the Interaction of Basic Dyes with Clays II: Thionine on Natural and Synthetic Montmorillonites and Hectorites. Journal of Colloid and Interface Science, 177, 495-501. http://dx.doi.org/10.1006/jcis.1996.0063

[36] Fujimoto, Y., Katayama, N., Ozaki, Y., Yasui, S. and Iriyama, K. (1992) Spectroscopic Studies of Thiatri-, Penta- and Heptamethine Cyanine Dyes II. Infrared and Resonance Raman Spectra of Thiatri-, Penta- and Heptamethine Cyanine Dyes. Journal of Molecular Structure, 274, 183-195. http://dx.doi.org/10.1016/0022-2860(92)80157-D

[37] Sato, H., Kawasaki, M., Kasatani, K. and Katsumata, M. (1988) Raman Spectra of Some Indo-, Thia- and SelenaCarbocyanine Dyes. Journal of Raman Spectroscopy, 19, 129-132. http://dx.doi.org/10.1002/jrs.1250190210

[38] Yang, J.P. and Callender, R.H. (1985) The Resonance Raman Spectra of Some Cyanine Dyes. Journal of Raman Spectroscopy, 16, 319-321. http://dx.doi.org/10.1002/jrs.1250160507

[39] Ras, R.H.A., Johnston, C.T., Franses, E.I., Ramaekers, R., Maes, G., Foubert, P., De Schryver, F.C. and Schoonheydt, R.A. (2003) Polarized Infrared Study of Hybrid Langmuir-Blodgett Monolayer Containing Clay Mineral Nanoparticles. Langmuir, 19, 4295-4302. http://dx.doi.org/10.1021/la026786r

[40] Cao, J.F., Wu, T., Hu, C., Liu, T., Sun, W., Fan, J.L. and Peng, X.J. (2012) The Nature of the Different Environmental Sensitivity of Symmetrical and Unsymmetrical Cyanine Dyes: An Experimental and Theoretical Study. Physical Chemistry Chemical Physics, 14, 13702-13708. http://dx.doi.org/10.1039/c2cp42122d 
Scientific Research Publishing (SCIRP) is one of the largest Open Access journal publishers. It is currently publishing more than 200 open access, online, peer-reviewed journals covering a wide range of academic disciplines. SCIRP serves the worldwide academic communities and contributes to the progress and application of science with its publication.

Other selected journals from SCIRP are listed as below. Submit your manuscript to us via either submit@scirp.org or Online Submission Portal.
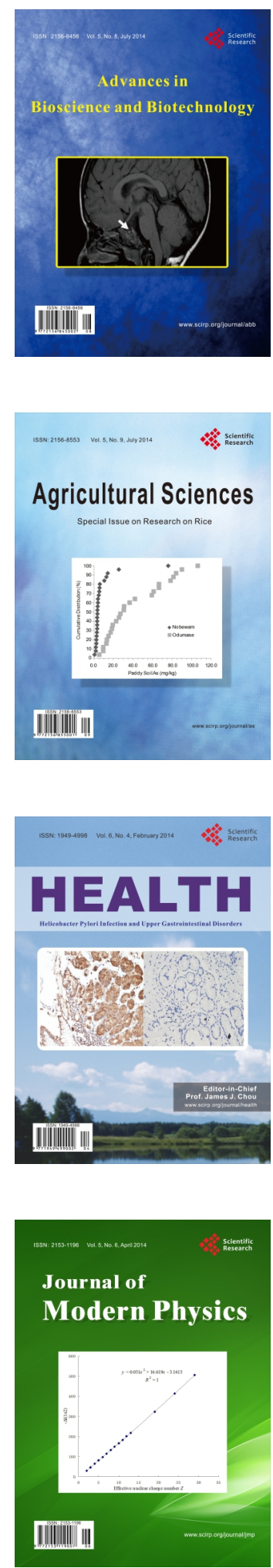
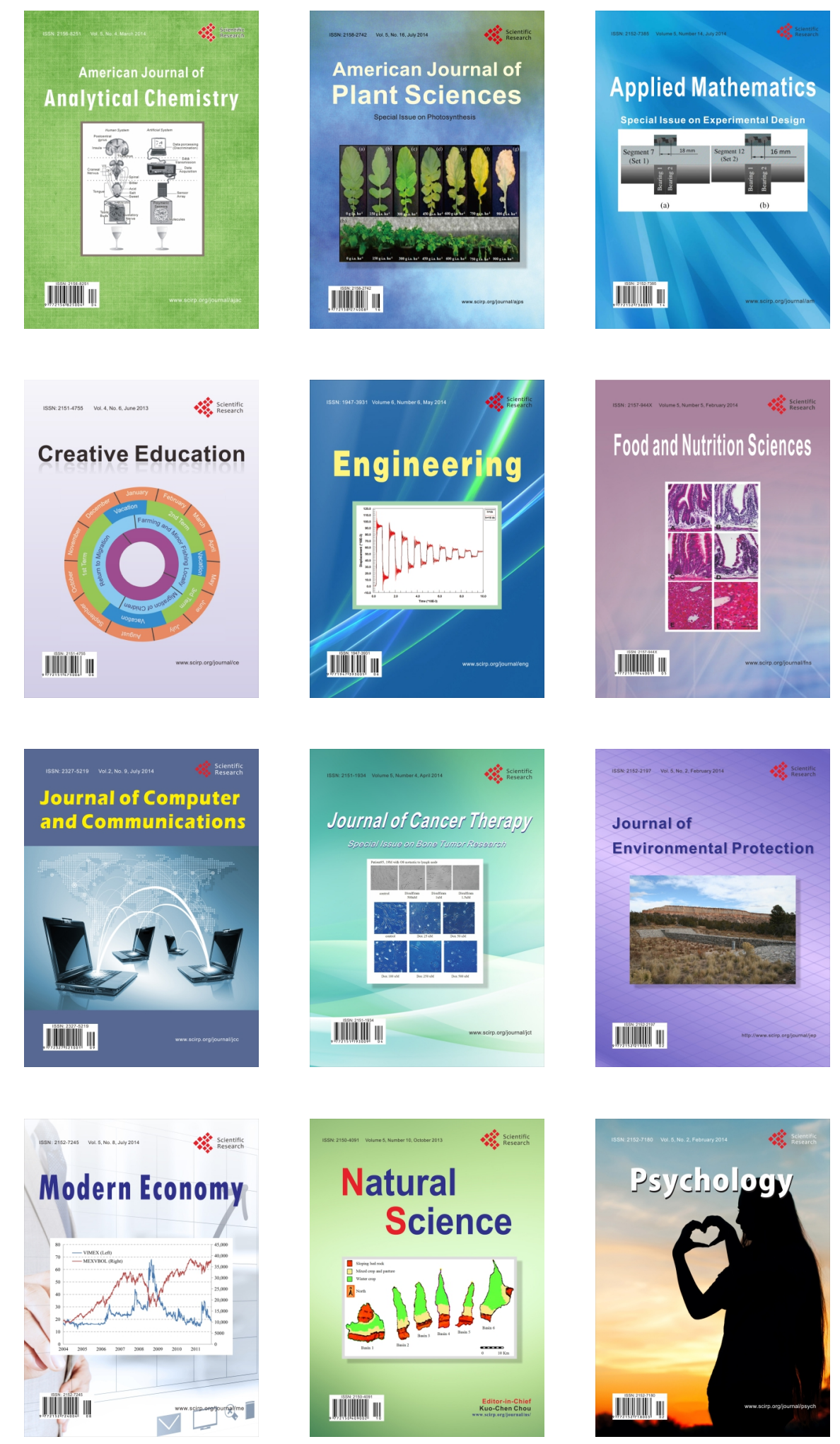